\title{
"ELEGANTES SILUETAS FEMENINAS Y LAS VARONILES FORMAS ARMONIOSAS": PRIMEROS ACERCAMIENTOS HISTÓRICOS SOBRE MUJERES Y CULTURA FÍSICA EN MONTEVIDEO
}

\author{
"ELEGANTES SILHUETAS FEMININAS E HARMONIOSAS FORMAS \\ VARONIS": PRIMEIRAS APROXIMAÇÕES HISTÓRICAS SOBRE \\ MULHERES E CULTURA FÍSICA EM MONTEVIDÉU
}

\author{
"ELEGANT FEMALE SILHOUETTES AND HARMONIOUS MALE FORMS": \\ INITIAL HISTORICAL APPROACHES ABOUT WOMEN AND PHYSICAL \\ CULTURE IN MONTEVIDEO
}

Alberto Noel Mallada Messeguer*, Evelise Amgarten Quitzau *

Palabras clave:

Historia.

Deportes.

Mujeres.

Uruguay.

Cultura física.

Palavras chave:

História.

Esportes.

Mulheres.

Uruguai.

Cultura física.

Keywords:

History.

Sports.

Women.

Uruguay.

Physical culture.
Resumen: El Uruguay del inicio del siglo XX pasaba por una gran transformación social y se mostraba como un país bastante abierto para reformas modernizadoras, en un proceso de creciente urbanización, secularización y nacionalización, especialmente en el área de Montevideo. En este escenario, una serie de políticas e intervenciones tenía enfoque en los cuerpos de la población y consideraba los ejercicios físicos como un elemento importante para su fortalecimiento y para la manutención de su salud. Nuestro objetivo es hacer un primer acercamiento al tema de las relaciones entre mujeres y cultura física en Uruguay, indagando sobre cuales prácticas les eran prescriptas y/o prohibidas a comienzos del siglo XX. Partiendo del análisis de revistas mundanas y deportivas publicadas en el área de Montevideo, se puede percibir la construcción de un ideal de mujer blanca, sana, joven y heterosexual a partir de prácticas como el tenis y la natación, principalmente

Resumo: O Uruguai do início do século XX passava por grandes transformações sociais, mostrando-se como um país bastante aberto para reformas modernizadoras, em um processo de crescente urbanização, secularização e nacionalização, especialmente na área de Montevidéu. Nesse cenário, uma série de políticas e intervenções tinham sua centralidade nos corpos da população e consideravam os exercícios físicos como um elemento importante para seu fortalecimento e para a manutenção de sua saúde. O objetivo deste artigo é fazer uma primeira aproximação ao tema das relações entre mulheres e cultura física no Uruguai, indagando sobre quais práticas Ihes eram prescritas e/ou proibidas no início do século XX. A partir da análise de revistas mundanas e esportivas publicadas na área de Montevidéu, pode-se perceber a construção de um ideal de mulher branca, saudável, jovem, heterossexual a partir de práticas principalmente como o tênis e a natação.

Abstract: In the early 20th century, Uruguay was undergoing important social changes. The country was apparently open to modernizing reforms, in a process of increasing urbanization, secularization and nationalization, especially in the Montevideo area. In this context, a series of policies and interventions focusing on the bodies of the population took place and saw physical exercise as an important element to strengthen those bodies and maintain health. This article is an initial aproach to relations between women and physical culture in Uruguay, examining which practices were prescribed and/or forbidden to them in early 20th century. Based on the analysis of regular and sports magazines published in the Montevideo area, we found the establishment of an ideal of woman - white, healthy, young and heterosexual - based especially on practices such as tennis and swimming.
${ }^{*}$ Centro Universitario Regional Norte. Sede Paysandu. Universidad de la Republica del Uruguay. Montevidéo, Uruguay. E-mail: albertomallada2016@gmail.com; equitzau@cup.edu.uy

Recebido em: 24-02-2019 Aprovado em: 23-03-2020 Publicado em: 24-04-2020 (c) (i) (8) Licence 


\section{INTRODUCCIÓN}

El área de la Historia de la Educación Física y del Deporte es un campo académico actualmente en construcción en Uruguay. Se puede percibir un esfuerzo sistematizado de investigaciones en este sentido a partir de los años 2000, con algunas tesis de maestría y doctorado (DOGLIOTTI, 2012; 2013; 2014; 2015; PÉREZ, 2016; RODRÍGUEZ, 2012; RUGGIANO, 2016; SCARLATO, 2015) que buscaron comprender el desarrollo de la Educación Física y los deportes en el contexto uruguayo, especialmente desde un punto de vista que podemos llamar "oficial", o como la educación del cuerpo se presentaba en distintos manuales de urbanidad que circularon en el país en las primeras décadas del siglo XX. Eso implica la existencia de un amplio abanico de temas y problemas respecto a la Educación Física y al Deporte todavía no estudiados desde una perspectiva histórica. Entre ellos se puede identificar las cuestiones de género en relación al ámbito de la cultura física, comprendida aquí en el sentido de David Kirk (1999, p.66), que afirma que la cultura física "es una forma especializada de discurso respecto a la producción de sentido centrada en las prácticas corporales constituidas por el deporte, la recreación y el ejercicio". Así, adoptar el concepto de cultura física nos permite comprender las prácticas corporales institucionalizadas más allá de sus aspectos biológicos, como espacios en que es posible observar distintos aspectos de las relaciones culturales y sociales que (re)producen discursos respecto al cuerpo. Entre estas relaciones están las de género en el ámbito de la cultura física, o más específicamente, la manera como distintos discursos han justificado prohibiciones y prescripciones que influenciaron la inserción de las mujeres en estas prácticas.

Silvana Goellner, al analizar las cuestiones epistemológicas referentes al uso de la categoría género específicamente en los estudios sobre historia del deporte afirma que

Como ferramenta analítica, o termo "gênero" possibilitou desconstruir a representação naturalizada de que homens e mulheres constroemse masculinos e femininos pelas diferenças corporais [...] Possibilitou, sobretudo, identificar que os corpos, as gestualidades, as representações de saúde, beleza, performance e sexualidade são construções históricas que, em diferentes tempos e culturas foram associadas aos homens e/ ou as mulheres, produzindo, ainda, representações de masculinidades e feminilidades (GOELLNER, 2007, p. 183)

La clave de género ha sido utilizada en estudios históricos sobre el deporte en países de América Latina para pensar como la cultura física ha contribuido para la construcción de distintas formas de masculinidad y feminidad. En Argentina, Pablo Scharagrodsky, por ejemplo, ha demostrado como la cultura física contribuyó para la concepción de determinados ideales hegemónicos de masculinidad y feminidad, insistentemente basados en una supuesta superioridad del organismo masculino frente al femenino (SCHARAGRODSKY, 2006a; 2006b; 2014). Goellner (2000; 2003; 2007), en Brasil, demostró como los ejercicios físicos sirvieron a los propósitos de constitución de un ideal de mujer sana, blanca y heterosexual cuyos grandes objetivos deberían ser desarrollar la belleza, la maternidad y la feminidad.

En los escenarios mencionados, la construcción de un ideal de feminidad a partir de determinados discursos, especialmente basados en el saber médico, ha 
determinado qué prácticas serian apropiadas o no a las mujeres. ¿Y en Uruguay? Si pensamos en el Uruguay de las primeras décadas del siglo $X X$, en pleno proceso de modernización y de importantes cambios urbanísticos, culturales y sociales, ¿qué prácticas y prescripciones respecto a las relaciones entre cultura física y mujeres podemos percibir en el escenario uruguayo?

El objetivo de este artículo es hacer un primer acercamiento al tema de las relaciones entre mujeres y cultura física en Uruguay, indagando sobre cuales prácticas les eran prescriptas y/o prohibidas en el país en comienzos del siglo XX. Para alcanzar este objetivo, utilizamos revistas publicadas en Montevideo en las tres primeras décadas del siglo XX. Comprendemos que este recorte temporal es bastante amplio y difuso, pero dado el vacío existente respecto al tema hemos optado por hacer, en esa incursión inicial, un rastreo un poco más amplio en términos temporales buscando identificar en que espacios aparecían registros de la relación de las mujeres con una cultura física.

Del gran universo de publicaciones impresas que circularon en el Uruguay del inicio del siglo $X X^{1}$, seleccionamos algunas revistas que pueden ser organizadas en dos grandes grupos. Un primer grupo es constituido por publicaciones especializadas sobre deporte, las revistas Rush:revista deldeporte uruguayo, publicadasemanalmente a partir de 1934 y con gran cantidad de fotografías, Deportes - Revista nacional ilustrada, que circuló desde 1930, y dos revistas denominadas Sportsman, una de 1908 llamada Sportsman - Revista semanal ilustrada, y otra llamada Sportsman Semanario sportivo ilustrado, de 1916.

El segundo grupo representa revistas de carácter más mundano, específicamente la Anales Mundanos, periódico que circuló en el país entre los años de 1915 y 1953. Inicialmente se caracterizaba como "revista álbum de la sociedad uruguaya" y según las palabras de su director jefe, César Álvarez Aguiar (1915, p.7), "surge [...] a cautivar el espíritu y la mentalidad de los que saben apreciar la virtud, la inteligencia, la distinción y la belleza de las damas uruguayas, cuyas semblanzas físicas y morales embellecerán las páginas de 'Anales Mundanos'”.

\section{MOLDEANDO CUERPOS, CONSTRUYENDO FEMINIDADES}

El Uruguay de las primeras décadas del siglo XX, según Gerardo Caetano (2015, p.22), era un país que "se mostraba más bien abierto para recibir e interpretar el impacto de los fenómenos típicos de la política moderna, desplegados con cierta comodidad en aquel país en gran medida nuevo y aluvional". El proceso de modernización del Estado uruguayo, conforme este autor, se estructuró a partir de seis ejes principales: económico, social, rural, fiscal, moral y político. Según Gianfranco Ruggiano (2016, p.30), estas transformaciones pueden ser identificadas a través de tres ejes: creciente urbanización, secularización más amplia y nacionalización.

Los cambios impulsados por la urbanización y las reformas sociales incidieron de una u otra manera sobre todos los ámbitos de la vida de la población, tornándola

1 Muchas de esas publicaciones están disponibles en el Portal Anáforas, un sitio web que reúne distintos periódicos publicados en el Uruguay desde el siglo XIX y es resultado de una acción de la Facultad de Información y Comunicación de la Universidad de la República (FIC/UdelaR). Sobre el Portal Anáforas ver: http://anaforas.fic.edu. uy/jspui/proyecto. 
objeto de las nuevas políticas. En este sentido, entre las acciones y políticas generadas a partir del proceso de modernización estaban aquellas que incidían directamente sobre el cuerpo, desde el ámbito médico hasta el educativo. Conforme Barrán (1995, p.33), el movimiento higienista que se difundía por el Uruguay formó parte de "un plan de moralización de las conductas", buscando alcanzar prioritariamente los sectores más jóvenes y populares en un intento de hacerlos evitar los "excesos", especialmente los de la carne. Para los representantes de este movimiento, el control sobre el propio cuerpo y, principalmente, sobre sus voluntades, sus deseos, era la principal clave para alcanzar la salud. El cuerpo pasa a ser objeto de acción directa de médicos y gobernantes, y una de las soluciones encontradas como forma de prevención a las molestias y de control de los deseos eran justamente los ejercicios físicos.

Estos cambios estructurales fueron acompañados de grandes movimientos sociales, como el feminista. Amanda Gómez (2015) al estudiar el movimiento feminista en el Río de la Plata, afirma que, en el Cono Sur, el feminismo se desarrolló especialmente en las capitales, a partir de los aportes de mujeres que inmigraron para los países latinoamericanos en fines del siglo XIX. Como afirma Barrán (1995), al mismo tiempo que el feminismo militante crecía y ganaba fuerza en sus luchas en pro de cuestiones como el lugar de la mujer en el mercado de trabajo o el derecho al aborto, la clase médica, tradicionalmente representada por miembros del patriarcado, intentaba determinar qué era lo femenino y lo masculino - y, por lo tanto, que sería permitido a hombres y mujeres -, basándose fundamentalmente en los aspectos biológicos de los cuerpos. Conforme Barrán (1995, p.97, subrayados del autor):

\begin{abstract}
La prédica en pro de la lactancia materna del niño para asegurar su salud, ocurrió en un Novecientos que asistía al comienzo de la revuelta femenina y la decadencia, por diferentes factores, del patriarcalismo. Se debe ver en esa prédica, además de la obsesión por la salud de la "raza", típico valor de época, un reflejo del temor masculino a la "liberación" de la mujer de su rol tradicional y un deseo de atarla con fuerza a ese papel.
\end{abstract}

Estas tensiones que se expresaban y reflejaban en los cuerpos tenían también gran influencia en su educación. Ruggiano (2016), a partir de estudio de manuales de urbanidad publicados en el Uruguay del Novecientos, afirma que se producía en el país una

[...] educación de los cuerpos de los niños, de las mujeres, etc. que siempre serán en relación de desigualdad y subordinación respecto al cuerpo hombre, adulto, urbano, de sectores dirigentes; en términos generales, educación de los cuerpos que permita una identificación y clasificación de todas aquellas alteridades que se diferenciaban de lo que se veía a sí mismo como lo uno. (RUGGIANO, 2016, p.113).

Este aspecto de desigualdad también se aprecia en nuestras fuentes del mismo período. En la revista Anales Mundanos (1916) se puede notar esta situación en un apartado de su edición $n^{\circ} 9$ intitulado "Los deberes de la esposa". El texto es presentado como una carta del escritor Diderot, hasta entonces ignorada, que habría sido sustraída del periódico parisiense "Le Temps". Escrito como una carta de un padre a su hija que se alejaba de casa porque recién se había casado, señala el deber de la esposa para con su marido, indicando a ella que "[...] haréis vuestra casa tan grata a vuestro marido, que no se apartará de ella sino con pena, si sois dulce, complaciente y alegre. Los negocios de afuera son de él; los de adentro 
son los vuestros". (DIDEROT, 1916, p. 16). En sus indicaciones, apunta para una posibilidad de que ella tenga alguna sociabilidad, siempre y cuando su marido crea conveniente, dando a entender que, en esa relación, él sería el único poseedor de sentido y razón. Al reproducir esta carta atribuida a un importante filósofo y escritor francés, la revista Anales Mundanos reproduce una serie de características que contribuyen para concretar modelos hegemónicos de masculinidad y feminidad en la sociedad uruguaya, indicándonos que el tipo ideal de mujer que se pretendía en el país era de una persona sumisa, que respondiese a su marido y a los mandatos sociales claramente establecidos. Así, limitaron a esa mujer del comienzo del siglo $X X$ en distintas esferas de la vida pública. Estas limitaciones señaladas no solo se visualizan en los textos, sino en las imágenes de las revistas, que esbozan posturas, vestimentas y actividades que eran permitidas a las mujeres.

Hasta aquí se vienen realizando reflexiones en cuanto a esa mujer del inicio del siglo $X X$, sus posibilidades y limitaciones en los ámbitos de su vida. Uno de esos ámbitos, que es el gran interés para este trabajo es el de la cultura física. En este sentido se toman los estudios de Paola Dogliotti (2013) que analizan la educación de los cuerpos en los proyectos de formación de maestros de Educación Física y de plazas de deportes entre finales del siglo XIX y comienzos del siglo XX, describiendo ciertas tensiones relacionadas al lugar que ocupó la mujer en las plazas de deporte. Allí, ellas estaban directamente asociadas con el cuidado de los niños a través de la organización espacial de dichas plazas: se presentaba un espacio para los varones y otro para las mujeres, pero este último con un espacio para alojar a niños y niñas menores de 6 años. La organización espacial de las plazas de deporte, por lo tanto, reproduce un discurso fuertemente en boga en el período: la mujer, en su rol de madre, era vista especialmente por los médicos higienistas como un importante agente de la salud pública, pues como responsable directa por la creación de los niños podría ayudar a rebajar la mortalidad infantil a partir de un cuidado responsable y científico, orientado por las determinaciones de la puericultura (LAVRIN, 2005, p. 140). Las plazas de deporte reproducían y afirmaban la simbiosis que debía existir entre la madre y sus hijos, lo que contribuía para limitar las posibilidades de acceso de la mujer a los distintos espacios de cultura física.

A pesar de estas limitaciones, igualmente se aprecia en algunas de las fuentes a la mujer vinculada con las prácticas deportivas, como el tenis. Este deporte subyace en varias ediciones de Anales Mundanos, donde se esbozan imágenes y textos que expresan sus beneficios para las mujeres. En artículo intitulado "EI Tennis", publicado en la edición $n^{\circ} 6$ de 1915, este deporte es caracterizado como una posible "novelería" que había producido un fervor tenístico que eventualmente podría perder fuerza y languidez, debido a los "antecedentes anti-deportivos" que presentaba el medio montevideano, resultando curioso y repentino que se lleve a cabo su implementación entre toda la población. Para el autor del artículo, el tenis representaba una excepción, pues todas las personas lo podían realizar, tanto niños, jóvenes, hombres y mujeres, independientemente de su clase social. Pero no todos lo realizaban en el mismo sitio: mientras la población de clase alta lo hacía en las aristócratas canchas de Pocitos o de Mrs. Williams, el resto de la población lo jugaba en las populares plazas de Deporte. 
Este deporte poseería varias ventajas, como la de "[...] provocar un amable acercamiento entre los sexos, hasta hoy distanciados, en actitud hosca y bravía, cada uno de ellos, fomentando una actividad social más intensa y razonable" (EL TENNIS, 1915, p. 11). Este acercamiento esboza una diferencia notoria con el análisis ya abordado que realiza Dogliotti (2013) en cuanto a la separación de hombres y mujeres en las plazas de deportes. Por lo menos en ese escenario más cercano de una élite montevideana representado en Anales Mundanos, el tenis producía un gran impacto, generando no solo desarrollos físicos en la población sino permitiendo un acercamiento entre hombres y mujeres.

La otra ventaja de este deporte refiere a la higiene y al agrado e interés que no poseen los otros deportes, teniendo en cuenta que los movimientos bien ejecutados "realzan las elegantes siluetas femeninas y las varoniles formas armoniosas" (EL TENNIS, 1915, p. 11). El tenis, por lo tanto, era una práctica permitida y mismo incentivada para las mujeres, una vez que contribuiría para reproducir la imagen de la mujer que se pretendía para la época, de aspecto "elegante" y "femenino".

Figura 1 - "El tennis"

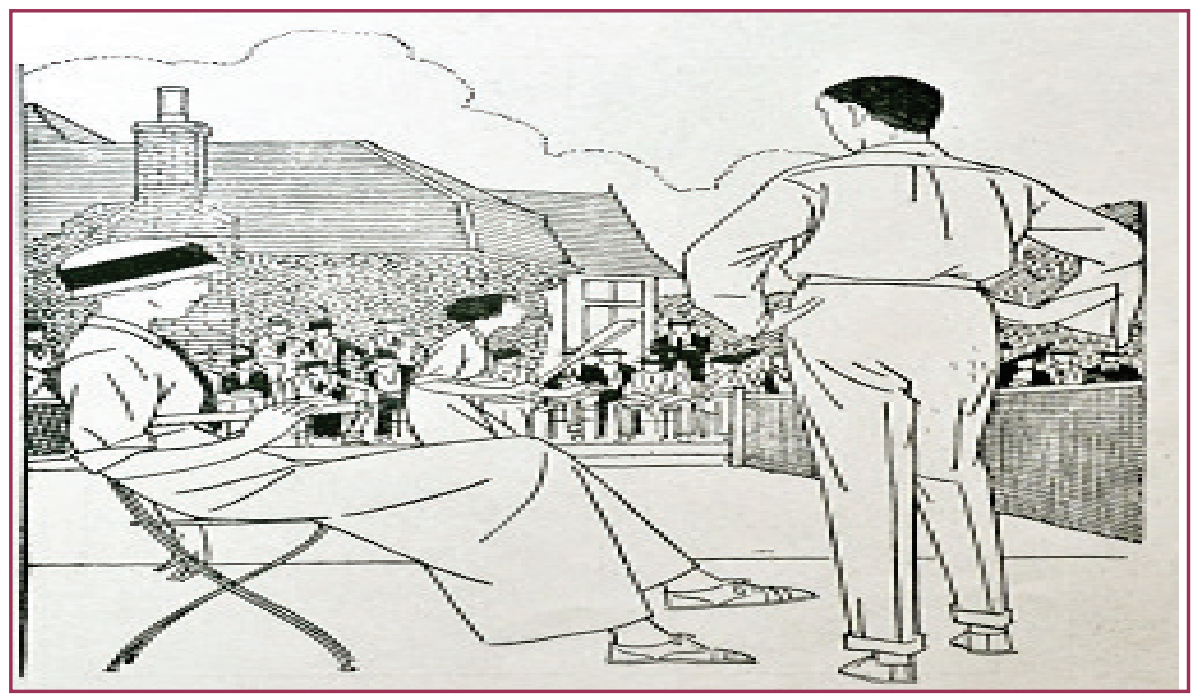

Fuente: Anales Mundanos, 1915, n. 6, p. 11 - Portal Anáforas

Figura 2 - "Deportes"

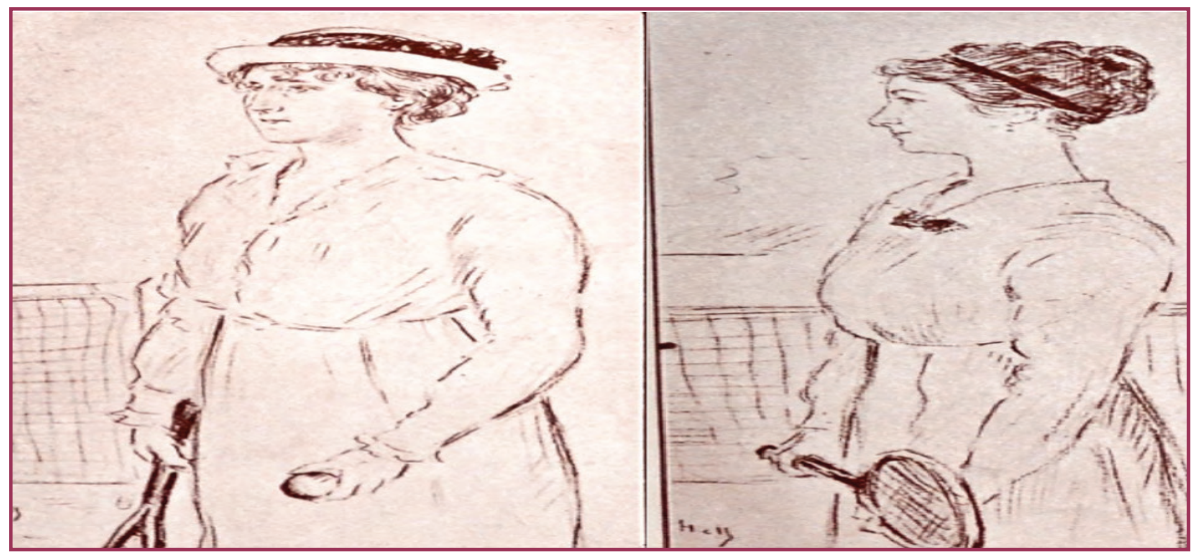

Fuente: Anales Mundanos, 1915, n. 3, p. 26 - Portal Anáforas

Observando las figuras 1 y 2 , se aprecia la vestimenta que utilizaban las mujeres, que seguramente se debía utilizar no por comodidad o practicidad al realizar 
el deporte, pues visiblemente este "uniforme" limitaba los movimientos e impedía su fluidez, algo distinto de lo que se ve en la fotografía de Hellen Wills, reconocida tenista estadounidense que ilustraba artículo sobre actualidades del tenis mundial publicado en la revista Deportes, en el año de 1930.

Figura 3 - "Actualidad del tenis mundial"

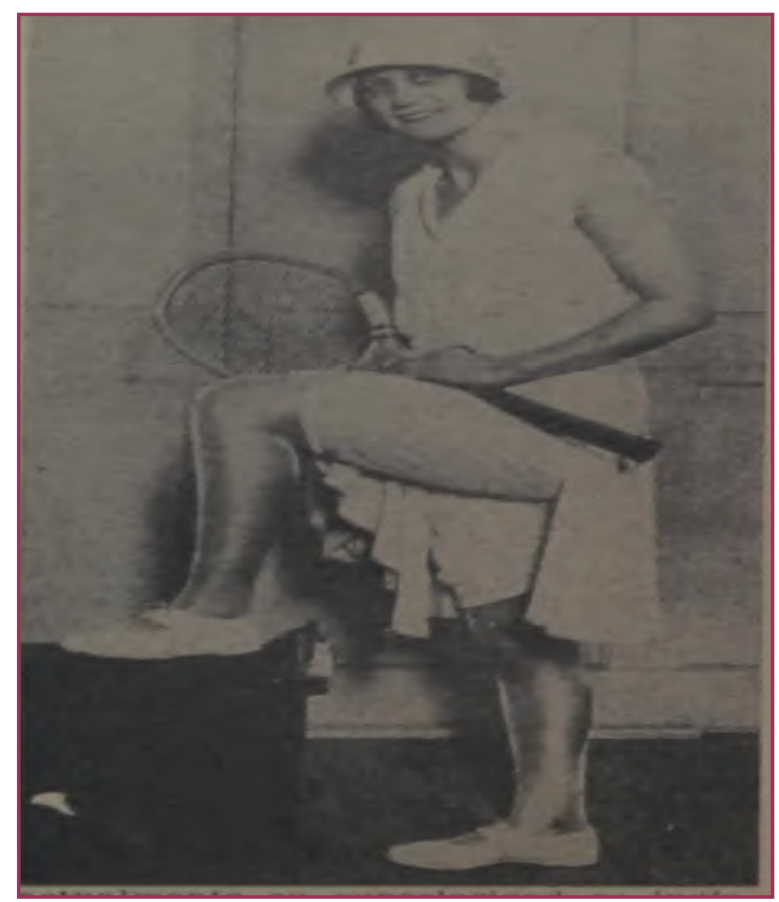

Fuente: Deportes, 1930, n. 5 p. 31 - Portal Anáforas

Estar atento a las ropas utilizadas por esta reconocida tenista que aparecía en las páginas de Deportes, así como en las representaciones gráficas de mujeres jugando tenis en Anales Mundanos, no es algo menor. Carmen Lucia Soares (2011) afirma que las vestimentas, a partir de los años 1920, contribuyeron para transformar valores estéticos y morales y constituían un elemento de distinción. Según la autora,

O esporte também se adjetiva nas roupas, e, se uma roupa esportiva é desenhada e vendida, se ela gera um mercado específico para ambos os sexos, ela gera, também, distinção entre os sexos. Assim, para as mulheres, a moda em geral - e mesmo a moda esportiva - foi sempre mais enfática no quesito "elegância" (SOARES, 2011, p.88, subrayados de la autora).

En el caso del tenis, mirando al escenario uruguayo, la prioridad de la elegancia en lugar del confort en las ropas deportivas femeninas es muy clara. Lo que es interesante observar en ese sentido es que mientras en la revista Anales Mundanos las ilustraciones de mujeres jugando el tenis las representan con vestidos largos, la fotografía de la atleta estadounidense publicada en el periódico especializado Deportes nos muestra ya una atleta con una vestimenta más corta y aparentemente más confortable, que le permite una mayor amplitud y eficacia en los movimientos durante un partido.

Los aspectos de lo que sería femenino que surgen del análisis de los textos sobre el tenis son tomados también por otros autores en otros países. Goellner (2000) en sus análisis sobre las imágenes del cuerpo de la mujer presentes en la Revista Educação Physica, publicada entre 1932 y 1945, identifica tres temas específicos: 
belleza, maternidad y feminidad. En cuanto a la belleza, entiende que es un fruto de la conquista que se visibiliza mediante un esfuerzo individual y para el cual es necesario trabajo arduo y constante según las recomendaciones y consejos que eran divulgados en la revista Educação Physica. Respecto al tema de la maternidad, Goellner (2000) sustrae de la revista los postulados que la identifican como una función social, siendo un destino y acontecimiento natural: el cuerpo femenino debería ser fuerte y sano porque tenía utilidad para la sociedad, por lo que se atribuyen diversas privaciones que tienen por objeto proteger las características de la feminidad y preservar la fertilidad de la mujer.

Podemos encontrar imagen similar de la mujer en las fuentes uruguayas. En estas también subyacen discursos sobre belleza, feminidad y maternidad, claramente asociados al cuidado de sus hijos, a las tareas domésticas y a cuidados en general. Esto es muy claro en artículo publicado en la revista deportiva Rush, de 1934, intitulado "Futbol coreográfico femenino". El artículo trae informaciones e imágenes de un encuentro de futbol de mujeres realizado en Madrid/España, presentándolo como una "curiosidad extranjera". Aquí son de gran relevancia dos aspectos: la palabra "coreográfico" en el título y el hecho de que nombra el torneo como "campeonato de piernas agiles y bonitas". Estos puntos enfatizan aspectos como la belleza de la mujer a través de sus "piernas bonitas" y la feminidad, al convertir el futbol en una coreografía, dando a entender que las prácticas corporales de la mujer deben poseer ese aspecto femenino, sutil, bello y estilizado. Al mismo tiempo en que estos términos resaltan determinados aspectos considerados como apropiados y deseables, la descripción del partido expresa no solo cierto juicio de valor por parte del autor, sino también cierta objetificación de estas mujeres "metidas a futbolistas":

De atenerse a lo que nos cuentan, habrá que convenir en que el partido fué disputadísimo y reñido en todo momento, cosa que tratándose de bataclanas, no nos toma de sorpresa. "Una técnica de juego completamente revolucionaria - nos advierten - se inauguró en el encuentro. Por lo visto para las bellas chicas de Eslava y Cervantes, metidas a futbolistas, vale todo... y para el público también, que en muchos momentos sintió veleidades de antropofagia" (FUTBOL COREOGRÁFICO FEMENINO, 1934, p. 2)

Figura 4 - El futbol coreográfico femenino

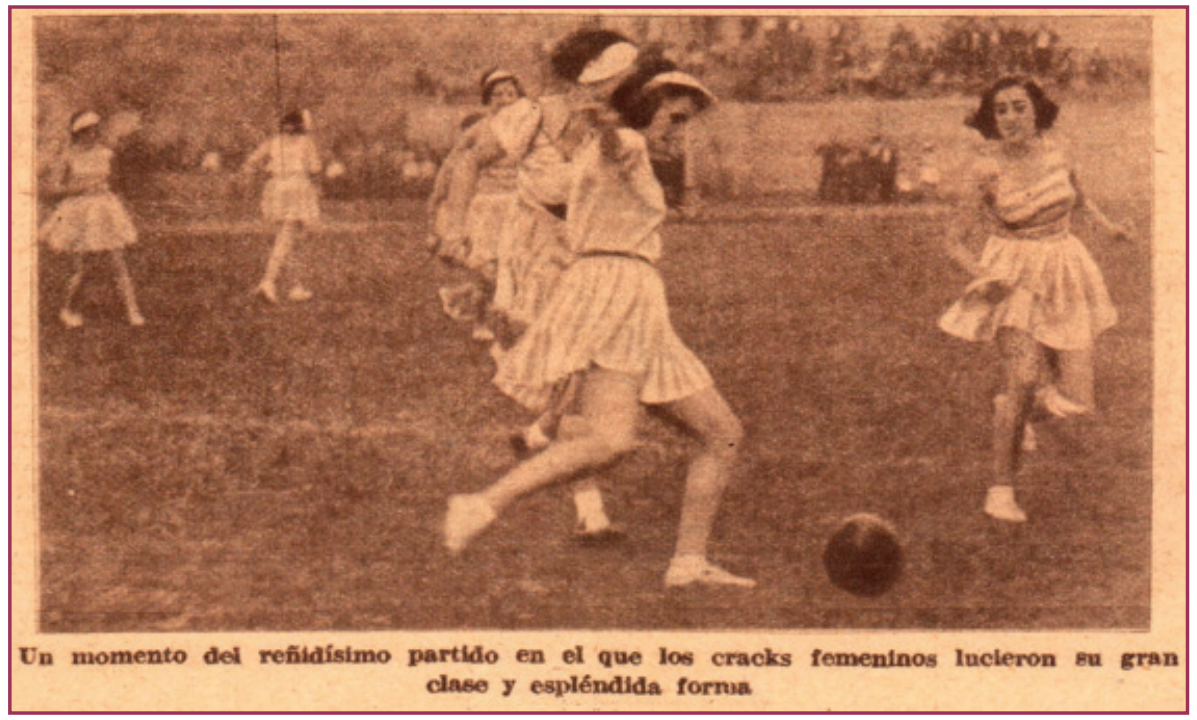

Fuente: Rush, 1934, n. 41, p. 2 - Portal Anáforas 
Goellner (2000), analizando el contexto brasileño, afirma que todos estos aspectos - belleza, sutileza, feminidad, maternidad - construyen una idea de mujer adulta joven, blanca, sana, heterosexual y de clase media, para las cuales las actividades físicas y deportivas, además de estar relacionadas con la construcción de un estado satisfactorio de salud, representan ejercicios de sociabilidad que las afirman en espacios tenidos como de dominio masculino. En este sentido, utilizando argumentos basados en los científicos del período, varios textos de la revista brasileña Educação Physica recomiendan la natación como el deporte más adecuado para mujeres, porque su técnica no exige demasiado desgaste físico, ni una musculatura muy desarrollada. Además de la natación, la danza es ampliamente recomendada, siendo considerada como la actividad corporal que mejor reúne los predicados que celebran su feminidad.

Estas prácticas permitidas para las mujeres en Brasil no estaban muy lejos de las permitidas en Uruguay. En la revista Deportes, un artículo denominado "Interesante clase de natación" promueve esta práctica para las mujeres, a partir de imágenes y textos que esbozan y relatan lo que acontece en Gran Bretaña con esta disciplina. Lo notorio es que no lo promueve a partir de argumentos médicos higiénicos, sino como una atracción al público masculino, refiriéndose a las mujeres nadadoras como "poseedoras de anatomías de 'vedettes' y ya sabemos lo que esto significa para estos públicos del Rio de la Plata [...]" y afirmando que: "cualquiera de ellas es capaz de obligar a colocar el deseado cartelito de "no hay mas localidades' en el mayor de nuestros coliseos con solo exhibirse en el traje elegido para las evoluciones en la clase" (INTERESANTE CLASE DE NATACIÓN, 1930 , p. 10). Pero ¿la única vinculación posible entre mujeres y deporte sería esa de la feminidad y, en un extremo, de cierta objetificación de su cuerpo? ¿No podría un deporte desarrollar la fuerza en la mujer y no regirse solamente por el modelo establecido de feminidad?

En los años 1930, es posible percibir también el surgimiento de un ideal de "mujer moderna". Eso se refleja, por ejemplo, en las páginas del semanario Anales Mundanos, en artículo intitulado "La mujer en el deporte". Aunque características como gentileza y elegancia sean utilizados para hablar de esa mujer que "triunfa con encantadora sencillez" (LA MUJER EN EL DEPORTE, 1937, p. 38), hay un énfasis en cierto deseo de cambio por parte de las mujeres prontas para "dominar distancias" o "presentarse con la arrogancia de una amazona del nuevo siglo". Aquí, ellas no aparecen más con elegantes ropas deportivas a jugar el tenis, ni con trajes de baño enfatizando sus "siluetas femeninas", sino en posiciones de dominio: dominio del caballo, del automóvil, del yacht.

Estos cambios a que se refiere el artículo son marcados no solo en el texto, sino principalmente en las tres grandes imágenes que lo acompañan: la de una mujer montando un caballo, otra manejando un auto y una tercera maniobrando un velero, donde se expresa que "hay un sentimiento en lo más hondo de todo ser humano, que lo siente en forma preferente la mujer, y es el deseo del cambio, de romper la monotonía del paisaje, de conquistar para sus ojos y para sus almas la novedad fresca de nuevos panoramas" (LA MUJER EN EL DEPORTE, 1937, p. 38). 
Frente a este lugar permitido para "ellas", es interesante mencionar un artículo presentado en la revista Rush de 1934, llamado "El deportivo femenino Capurro es un club de verdad", que presenta las actividades que se desarrollan en el espacio del balneario por el Club Capurro, primer grupo de mujeres jóvenes después de la Asociación Cristiana Femenina. Este artículo plantea una gran relevancia a este tipo de organizaciones, ya que llevan a cabo actividades enriquecedoras, teniendo en cuenta que en la mayoría de las playas faltaban espacios para la recreación y el deporte. En el documento se aprecia a través de textos e imágenes la realización de varios deportes, como voleibol, gimnasia, tenis, basquetbol, hockey, atletismo y natación. Con la implementación de estas actividades se crea día a día un núcleo de hábitos, lo que llevó a que "el elemento femenino se ha rebelado contra la inacción, y así ha llevado a la playa los medios para hacer deporte". (EL DEPORTIVO FEMENINO..., 1934, p. 12).

Uno de los aportes que se puede analizar es la postura que se denota en el texto y en imágenes de la figura masculina, estableciendo que han encontrado excelente la idea de fijar en las playas tableros de basquetbol, ya que les permite "echarse a dormir" debajo de ellos. Este punto aporta una visión de las "otras miradas" cuando las mujeres realizan actividades deportivas, y nos preguntamos ¿este aspecto influye en limitar la realización de prácticas corporales de las mujeres?

Figura 5 - "El deportivo femenino Capurro es un club de verdad".

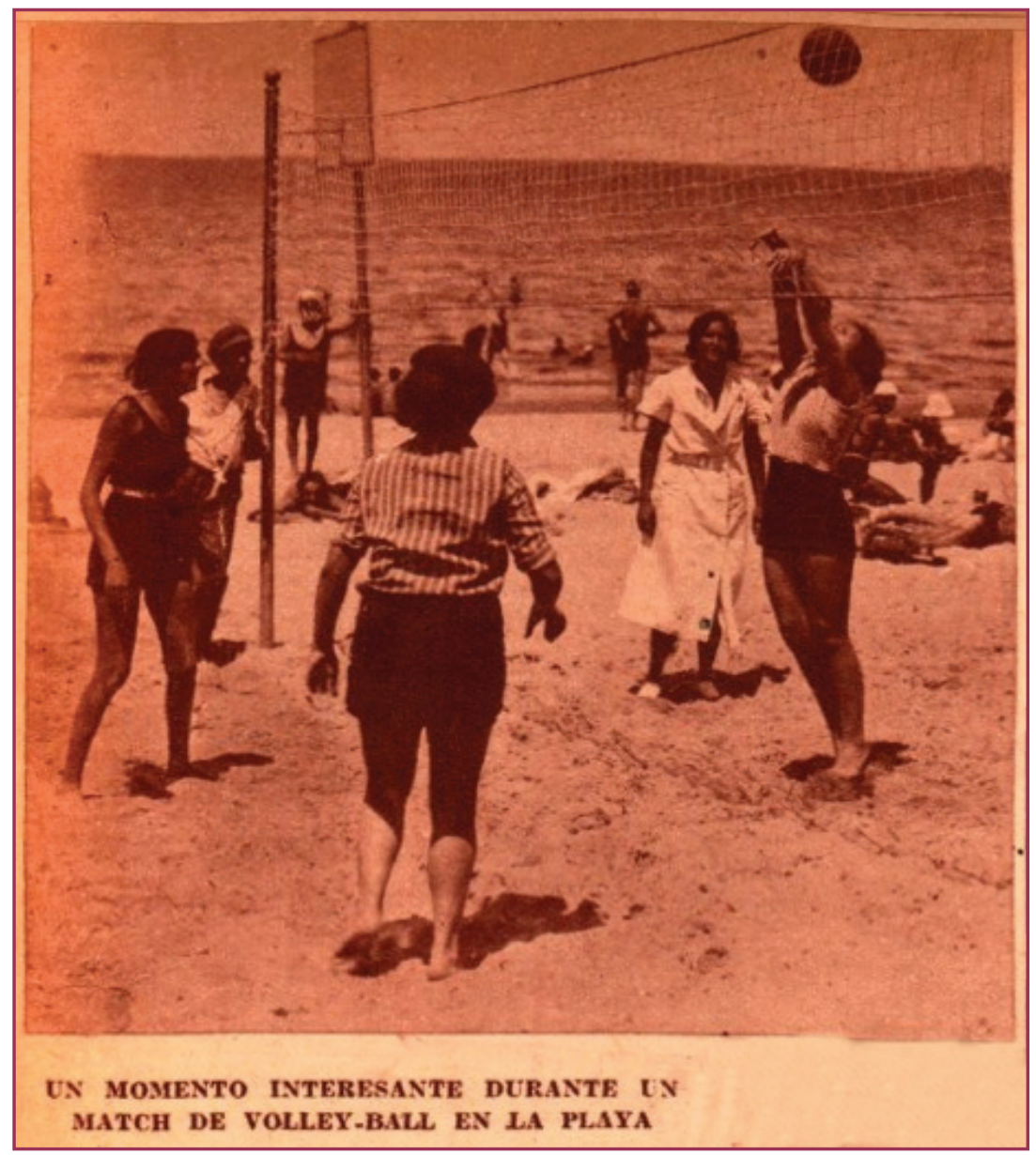

Fuente: Rush, 1934, n 30, p. 12 - Portal Anáforas 
Figura 6 - "El deportivo femenino Capurro es un club de verdad".

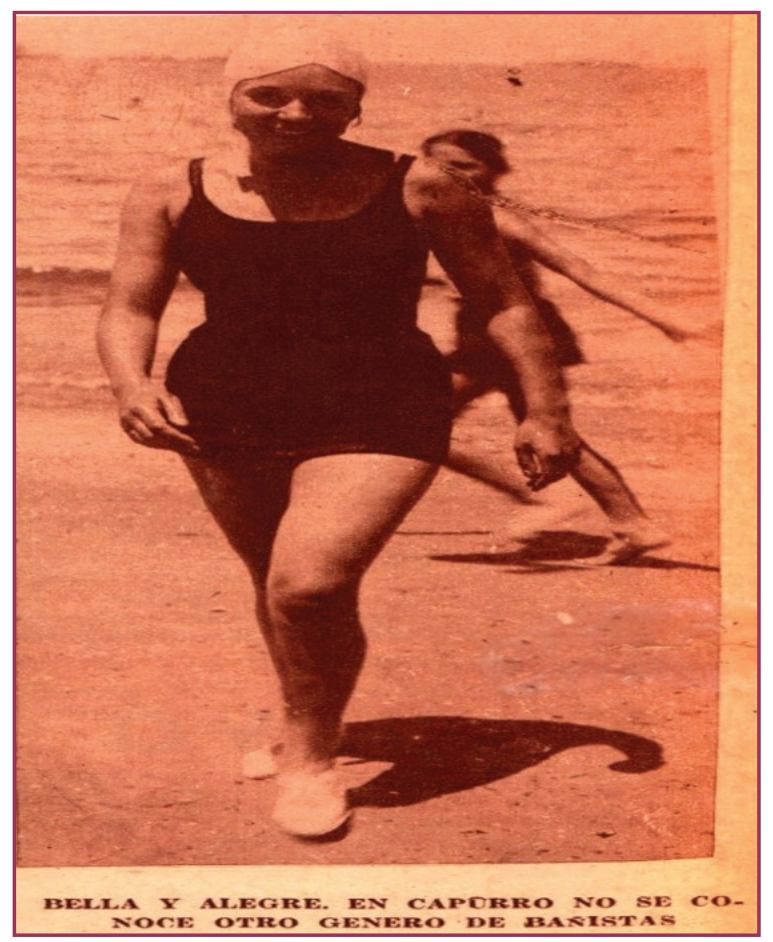

Fuente: Rush, 1934, n. 30, p. 13 - Portal Anáforas

A primera vista, estas miradas de los hombres no influyen en la ejecución de prácticas deportivas de las mujeres en la playa Capurro. Se visualiza en la figura 5 un grupo de mujeres practicando voleibol de playa, pero si miramos atentamente junto al poste que sostiene la red y contiguo al tablero de basquetbol surgen esas miradas masculinas. Ya sea en la tierra o en el agua, se aprecia a las mujeres "bellas y alegres", con posturas de reivindicación, que no se limitaban ni con las miradas masculinas. Realizan un despliegue deportivo que les ha permitido un desarrollo tanto corporal, como social claramente marcado en el artículo. Por esto "la playa Capurro" representa un espacio que se debía reproducir en otros lugares, promovido por la revista Rush al publicar el mencionado artículo de dos páginas, que indica que se continuaría con la promoción de este espacio, pues "la obra proyectada es amplia y seguramente merecerá más de una vez los honores de la publicación" (EL DEPORTIVO FEMENINO..., 1934, p. 13).

En concordancia con lo mencionado del artículo de la revista Rush, se sustrae los aportes que realiza Maria Paula Bontempo (2016) al analizar la revista argentina "Para Ti", de 1922. La autora selecciona y estudia específicamente los aportes esbozados en artículo denominado "La cultura física en la mujer" del Dr. Cesar Sánchez Azicorbe, que reconocía y fomentaba la cultura física femenina y la práctica de deportes. Según Bontempo, el doctor Sánchez Azicorbe "[...] se alista entre aquellos que dudaban de la debilidad femenina y, por el contrario, le asignaba valores morales que justificaban la "emancipación" de la mujer" (BONTEMPO 2016, p.335). Estos valores morales que apuntaban al fortalecimiento de la mujer en la sociedad, también surgen del análisis de la revista uruguaya Deportes, donde en artículo denominado "Una de las más bellas atletas del orbe" (1930), la atleta italiana Marina Zanetti (descripta por la revista como una de las mejores lanzadoras 
de disco de la época y luchadora incansable del progreso del deporte femenino) subraya la importancia del deporte para las mujeres. Su postura es de crítica a la cultura física italiana que, en lo que refiere a las mujeres, hasta el momento se había limitado a sesiones de gimnasia dos veces por semana, sin "deportes organizados, ni campeonatos, ni competencias escolares" (UNA DE LAS MÁS BELLAS ATLETAS DEL ORBE, 1930, p.1). Zanetti, por lo tanto, reivindica el derecho de las mujeres a participar efectivamente del ámbito deportivo, y la reproducción de sus ideas en esta revista uruguaya posee un gran sentido, pues alienta a la posibilidad de lucha y participación en nivel competitivo de las mujeres en el deporte. Señala, en este sentido, una búsqueda de ruptura de las desigualdades que estaban claramente denotadas en comparación con las posibilidades de los hombres en cuanto a la realización de cualquier tipo de práctica corporal.

\section{CONSIDERACIONES FINALES}

El presente artículo constituye un primer acercamiento histórico sobre las cuestiones referentes a las mujeres y la cultura física en Uruguay, más específicamente en el área de Montevideo. Con un recorte temporal amplio, que abarca desde los primeros años del siglo XX hasta fines de la década de 1930, buscamos rastrear cuáles eran las prácticas corporales posibles para las mujeres en el país en ese período. A partir del análisis de revistas mundanas y deportivas nos fue posible percibir una serie de discursos que, en general, buscaron construir un ideal de mujer muy similar al que ya ha sido observado en otros países, como Argentina y Brasil: blanca, sana, joven, heterosexual. Mujer que estaba regida por discursos hegemónicos que la potenciaron desde lo bello, femenino y elegante, aspectos que se debían desarrollar con muchas de las practicas corporales permitidas para ellas.

Es ese ideal de mujer que se presenta mayoritariamente en las fuentes consultadas y que debería ser alcanzado especialmente a partir de prácticas como el tenis y la natación. En Uruguay se encuentran también registros de mujeres practicando yachting, equitación, automovilismo, atletismo, golf en miniatura, voleibol, gimnasia y hockey, al mismo tiempo en que se divulgaban prácticas efectuadas en otros países, como el futbol, cross country y atletismo. Entretanto, en este intento de construir un tipo ideal de mujer, es posible percibir especialmente a partir de los años 1930, la emergencia de algunos discursos que indican la vinculación de las mujeres a ideales de modernidad y a un deseo de cambio, sugiriendo una aparente alteración en este tipo ideal de mujer y una ampliación del universo de la cultura física femenina uruguaya.

\section{REFERENCIAS}

ACTUALIDAD del tenis mundial. Deportes, n. 5, p. 31, 1930.

ALVAREZ AGUIAR, César. Presentación de la revista Anales Mundanos. Anales

Mundanos, a. 1, n. 1, p. 7, 1915. 
BARRÁN, José Pedro. Medicina y sociedad en el Uruguay del Novecientos. Tomo III La invención del cuerpo. Montevideo: Ediciones de la Banda Oriental, 1995.

BONTEMPO, Maria Paula. El cuerpo de la mujer moderna. La construcción de la femeninidad en las revistas de Editorial Atlántica, 1918-1933. In: SCHARAGRODSKY, Pablo Ariel. Mujeres en movimiento. Argentina: Prometeo Libros, 2016. p. 329-348

CAETANO, Gerardo. La república batllista: ciudadanía, republicanismo y liberalismo en Uruguay (1910-1933). Montevideo: Ediciones de la Banda Oriental, 2015.

DEPORTES. Anales Mundanos, n. 3, p. 26, 1915.

DIDEROT. Los deberes de la esposa. Anales mundanos, n. 9, p. 16, 1916.

DOGLIOTTI, Paola. Acerca de la "Cultura Física" en la revista Uruguay-Sport: Archivos de la CNEF, Uruguay (1918-1926). Revista Brasileira de Ciências do Esporte, v.36, n.3, 2-14, p.608-616, 2014. Disponible en: http://www.scielo.br/pdf/rbce/v36n3/0101-3289rbce-36-03-0608.pdf. Acceso en: 27 mar. 2020.

DOGLIOTTI, Paola. Educación del cuerpo y discursividades en torno a la formación en Educación Física en Uruguay (1874-1948). Montevideo: Ediciones Universitarias, 2015.

DOGLIOTTI, Paola. Educación del cuerpo, higiene y gimnástica en la conformación de la educación física escolar en el Uruguay (1874-1923). Historia de la educación - anuario, v. 13, n. 2, p. 1-21, 2012. Disponible en: http://www.scielo.org.ar/scielo.php?script=sci arttext\&pid=S2313-92772012000200004\&lng=es\&tlng=es. Acceso en: 27 mar. 2020.

DOGLIOTTI, Paola. La formación de maestros de educación física en el Uruguay (19211930): Julio J. Rodríguez. História da Educação, v.17, n.41, p.139-158, 2013. Disponible en: http://www.scielo.br/pdf/heduc/v17n41/09.pdf. Acceso en: 27 mar. 2020.

EL DEPORTIVO femenino Capurro es un club de verdad. Rush, n. 30, p. 12, 1934.

EL TENNIS. Anales Mundanos, n. 6, p. 11, 1915

FÚTBOL coreográfico femenino. Rush, n. 41, p. 2, 1934

GOELLNER, Silvana Vilodre. "Mulheres em movimento: imagens femininas na Revista Educação Physica". Educação e realidade, v. 25, n. 2, p. 77-94, 2000. Disponible en: http:// seer.ufrgs.br/index.php/educacaoerealidade/article/view/46836. Acceso en: 27 mar. 2020.

GOELLNER, Silvana Vilodre. Bela, maternal e feminina: imagens da mulher na Revista Educação Physica. ljuí: Unijuí, 2003.

GOELLNER, Silvana Vilodre. Feminismos, mulheres e esportes: questões epistemológicas sobre o fazer historiográfico. Movimento. v. 13, n. 2, p. 171-196, 2007. Disponible en: http:// seer.ufrgs.br/index.php/Movimento/article/view/3554. Acceso en: 27 mar. 2020.

GÓMEZ, Amanda. Elvira López: pionera del feminismo en la Argentina. Cuyo, v. 32, n.1, p. 17-37, 2015. Disponible en: http://www.scielo.org.ar/scielo.php?script=sci arttext\&pid=S1853-31752015000100002\&Ing=es\&tIng=es. Acceso en: 27 mar. 2020.

INTERESANTE clase de natación. Deportes, n. 5, p. 10, 1930

KIRK, David. Physical Culture, Physical Education and Relational

Analysis. Sport, Education and Society, v.4, n.1, p. 63-73, 1999. Disponible en: http://

dx.doi.org/10.1080/1357332990040105. Acceso en: 27 mar. 2020. 
LA MUJER en el deporte. Anales mundanos, n.114, p.38, 1937.

LAVRIN, Asunción. Mujeres, feminismo y cambio social en Argentina, Chile y Uruguay 1890-1940. Santiago de Chile: Dirección de Bibliotecas, Archivos y Museos, 2005.

PÉREZ MONKAS, Gonzalo. La (des)aparición de las prácticas corporales sometidas: una arqueología en el Uruguay del siglo XIX (1861-1871). Tesis [maestría] - Universidad Nacional de La Plata. Facultad de Humanidades y Ciencias de la Educación, 2016. Disponible en: http://www.memoria.fahce.unlp.edu.ar/tesis/te.1331/te.1331.pdf. Acceso en: 27 mar. 2020.

RODRÍGUEZ, Raumar. Saber del cuerpo: una exploración entre normalismo y universidad en ocasión de la educación física (Uruguay, 1876-1939). Tesis [maestría] - Universidad de la República; Facultad de Humanidades y Ciencias de la Educación. Montevideo, 2012.

RUGGIANO LOPEZ, Gianfranco. Ser un cuerpo educado: urbanidades en el Uruguay (1875-1918). Tese [Doutorado em Educação] - Universidade Estadual de Campinas; Faculdade de Educação. Campinas, 2016.

SCARLATO, Inés. Corpo e tempo livre: as plazas vecinales de cultura física em Montevideu (1911-1915). Dissertação [Mestrado em Educação] - Universidade Federal de Santa Catariana. Florianópolis, 2015.

SCHARAGRODSKY, Pablo Ariel. (org.) Miradas médicas sobre la cultura física en Argentina (1880-1970). Buenos Aires: Prometeo Libros, 2014.

SCHARAGRODSKY, Pablo Ariel. 'Ejercitando' los cuerpos masculinos y femeninos. Aportes para una historia de la educación física escolar argentina (1880-1990). Apunts. Educación física y deportes, 2006 , v. 3, n. 85, p. 92-89, 2006a. Disponible en: https://www.raco.cat/ index.php/ApuntsEFD/article/view/300853. Acceso en: 27 mar. 2020.

SCHARAGRODSKY, Pablo Ariel. Género, masculinidades y educación física - varones exitosos y varones devaluados. In: AISENSTEIN, Ángela. Cuerpo y cultura: prácticas corporales y diversidad. Buenos Aires: Libros del Rojas, 2006b. p. 163-184.

SOARES, Carmen Lucia. As roupas destinadas aos exercícios físicos e ao esporte: nova sensibilidade, nova educação do corpo (Brasil, 1920-1940). Pro-Posições, v. 22, n. 3 (66), p. 81-96, 2011. Disponible en: http://www.scielo.br/pdf/pp/v22n3/07.pdf. Acceso en: 27 mar. 2020.

SPORTSMAN - revista nacional ilustrada, a. 1, n. 1, p. 6, 1908.

UNA DE LAS MÁS bellas atletas del orbe. Deportes, n. 5, p. 8, 1930. 